\title{
BANGKITAN DAN TARIKAN PERGERAKAN DI KAWASAN PENDIDIKAN KOTA BANDAR LAMPUNG
}

\author{
Shahnaz Nabila Fuady \\ Program Studi Perencanaan \\ Wilayah dan Kota \\ Institut Teknologi Sumatera \\ Jln. Terusan Ryacudu, Way Huwi \\ Kecamatan Jati Agung \\ Kabupaten Lampung Selatan \\ bellafuady@pwk.itera.ac.id
}

\author{
Divia Indira Arifin \\ Program Studi Perencanaan \\ Wilayah dan Kota \\ Institut Teknologi Sumatera \\ Jln. Terusan Ryacudu, Way Huwi \\ Kecamatan Jati Agung \\ Kabupaten Lampung Selatan \\ diviaindira@gmail.com
}

\author{
Aleksander Purba \\ Program Studi Program \\ Pendidikan Insinyur \\ Universitas Lampung \\ Jln. Prof. Dr. Sumantri \\ Brojonegoro No. 1 \\ Bandar Lampung \\ aleksander.purba@eng.unila.ac.id
}

\begin{abstract}
The movement of people to fulfill their needs must be well planned, so that traffic congestion can be avoided. The increasing population in Bandar Lampung has an impact on the number of movements as a whole, and one of them is in the school area on Jalan Cendana-Jalan Ir. H. Juanda. This study aims to determine the generation and attraction models of movement in the school area, on Jalan Cendana-Jalan Ir. H. Juanda, Bandar Lampung. This study shows that the factors that influence the trip generation and trip attraction in the study area are the number of classrooms, the number of teachers and staffs, and student daily allowances. In addition, the trip generation and trip attraction that occur are large enough to affect traffic, especially in the morning, which indicates high land use activities in the morning in the area.
\end{abstract}

Keywords: school area; traffic congestion; trip generation; trip attraction.

\begin{abstract}
Abstrak
Pergerakan manusia untuk memenuhi kebutuhannya harus direncanakan dengan baik, agar kemacetan lalu lintas dapat dihindari. Jumlah penduduk di Kota Bandar Lampung yang terus meningkat berdampak pada jumlah pergerakan secara keseluruhan, dan salah satunya pada kawasan pendidikan di Jalan Cendana-Jalan Ir. H. Juanda. Penelitian ini bertujuan untuk mengetahui model bangkitan dan tarikan pergerakan di kawasan pendidikan, di Jalan Cendana-Jalan Ir. H. Juanda, Bandar Lampung. Studi ini menunjukkan bahwa faktorfaktor yang memengaruhi bangkitan dan tarikan pergerakan di wilayah studi adalah jumlah ruang kelas, jumlah guru dan tenaga kependidikan, serta uang saku murid per hari. Selain itu, bangkitan dan tarikan pergerakan yang terjadi cukup besar untuk memengaruhi lalu lintas, terutama di pagi hari, yang menandakan tingginya aktivitas guna lahan pada pagi hari di kawasan tersebut.
\end{abstract}

Kata-kata kunci: kawasan pendidikan; kemacetan lalu lintas; bangkitan pergerakan; tarikan pergerakan.

\section{PENDAHULUAN}

Jumlah penduduk di Kota Bandar Lampung yang setiap tahunnya mengalami peningkatan berdampak pada jumlah pergerakan secara keseluruhan (BPS Kota Bandar Lampung, 2020). Pada akhirnya hal tersebut menimbulkan masalah pergerakan, seperti kemacetan lalu lintas, yang terjadi pada jam sibuk di beberapa ruas jalan utama.

Salah satu tempat yang rawan kemacetan lalu lintas adalah kawasan pendidikan di sekitar Jalan Cendana dan Jalan Ir. H. Juanda, yang mana terdapat 5 sekolah di kawasan tersebut, yaitu KB/TK Fransiskus 2 Bandar Lampung dan SD Fransiskus 2 Bandar Lampung, yang berlokasi di Jln. Ir. H. Juanda No. 10 C, SD Negeri 2 Rawa Laut Bandar Lampung, 
yang berlokasi di Jln. Cendana No. 33, serta SMP Xaverius 2 Bandar Lampung dan SMA Xaverius Bandar Lampung, yang berlokasi di Jln. Cendana No. 31. Kelima sekolah tersebut memiliki letak yang berdekatan dengan wilayah administrasi di Kelurahan Rawa Laut, Kecamatan Enggal.

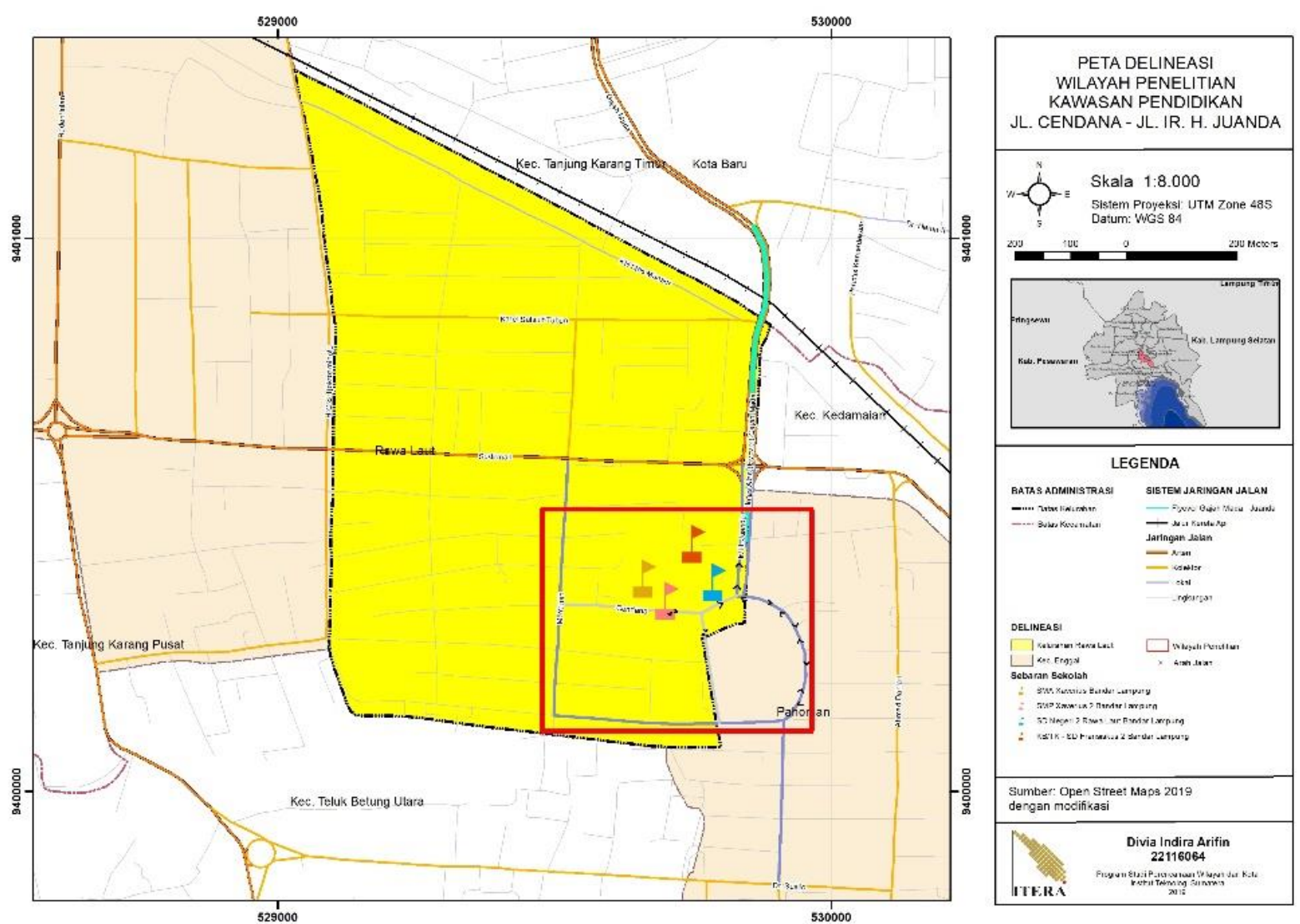

Gambar 1 Peta Delineasi Wilayah Penelitian

Kawasan pendidikan merupakan suatu tempat yang rawan terjadi kemacetan lalu lintas, terutama pada jam masuk dan jam pulang sekolah (Septomiko, 2014). Pergerakan yang terjadi di kawasan pendidikan disebabkan oleh banyaknya murid yang bersekolah jauh dari tempat tinggalnya, sehingga pergerakan dilakukan dengan menggunakan kendaraan (Ilyani, 2012). Berdasarkan hal tersebut, perlu diketahui faktor-faktor yang memengaruhi pergerakan pada kawasan pendidikan di Jalan Cendana-Jalan Ir. H. Juanda, Kota Bandar Lampung, untuk mencegah masalah pergerakan di kemudian hari (lihat Gambar 1). Penelitian ini diharapkan dapat memberikan wawasan mengenai penerapan model bangkitan dan tarikan pergerakan untuk mengetahui faktor-faktor yang memengaruhi pergerakan berkenaan dengan aktivitas pada guna lahan tertentu, serta menjadi landasan dalam memberikan solusi transportasi yang berkelanjutan.

\section{Bangkitan Pergerakan}

Bangkitan pergerakan (trip generation) merupakan jumlah pergerakan yang diakibatkan oleh aktivitas yang ada di suatu zona (kawasan) per satuan waktu (Sholichin, 
2011). Bangkitan pergerakan merupakan tahap pertama pada Model Perencanaan Empat Tahap/Four Stages Model, yaitu perkiraan atas jumlah pergerakan yang berasal dari zona tertentu atau tertarik ke zona tertentu (Tamin, 1997). Dengan kata lain, pergerakan akibat aktivitas yang ada di zona atau lahan tertentu menghasilkan bangkitan pergerakan yang mencakup pergerakan meninggalkan suatu zona dan menuju ke suatu zona (Wahyuningsih et al., 2013).

Ortúzar dan Willumsen (1990) mengemukakan bahwa terdapat sejumlah variabel yang memengaruhi pergerakan meninggalkan suatu zona, seperti pendapatan, kepemilikan kendaraan, jumlah anggota keluarga, struktur rumah tangga, nilai lahan, kepadatan permukiman, dan aksesibilitas. Manoppo dan Sendow (2011), dalam penelitiannya, menggunakan variabel komposisi keluarga, jumlah anggota keluarga yang bekerja, jumlah anggota keluarga yang belajar, jumlah anggota keluarga yang bekerja dan belajar, kepemilikan kendaraan, serta penghasilan keluarga, yang dirasa berhubungan dengan produksi pergerakan. Sholichin (2011) memperjelas variabel kepemilikan kendaraan berdasarkan jenis moda, yaitu mobil pribadi, sepeda motor, dan angkutan umum. Adapun variabel yang memengaruhi pergerakan menuju suatu zona adalah luas lantai kegiatan industri, komersial, perkantoran, pertokoan, serta pelayanan lainnya (Tamin, 1997). Sedangkan variabel yang memengaruhi bangkitan pergerakan barang adalah jumlah tenaga kerja, jumlah penjualan, luas atap firma, dan luas firma secara keseluruhan (Ortúzar dan Willumsen, 1990).

\section{Model Regresi Linier Berganda}

Metode yang sering digunakan pada analisis bangkitan pergerakan adalah metode regresi linier berganda (Multiple Linear Regression Analysis). Bentuk model regresi linier berganda tersebut adalah:

$$
Y=a+b_{1} X_{1}+b_{2} X_{2}+\cdots+b_{n} X_{n}
$$

dengan:

$\mathrm{Y}=$ Jumlah pergerakan per hari (variabel tidak bebas)

$\mathrm{X}_{1}, \ldots, \mathrm{X}_{\mathrm{n}}=$ Faktor-faktor yang memengaruhi (variabel bebas)

A $\quad=$ Konstanta regresi (angka yang akan dicari)

$\mathrm{b}_{1}, \ldots, \mathrm{b}_{\mathrm{n}}=$ Koefisien regresi (angka yang harus dicari).

\section{METODOLOGI}

Pada studi ini dilakukan survei pada 5 sekolah yang terdapat di sekitar Jalan Cendana-Jalan Ir. H. Juanda, Kota Bandar Lampung. Kelima sekolah tersebut adalah: (1) KB/TK Fransiskus 2 Bandar Lampung, (2) SD Fransiskus 2 Bandar Lampung, (3) SD Negeri 2 Rawa Laut Bandar Lampung, ((4) SMP Xaverius 2 Bandar Lampung, dan (5) SMA Xaverius Bandar Lampung. 
Pendekatan yang digunakan pada penelitian ini adalah pendekatan kuantitatif, yaitu suatu pendekatan untuk menguji teori dengan memeriksa hubungan antarvariabel terukur dengan data berupa angka (Creswell, 2003). Berdasarkan pendekatan ini, analisis yang digunakan adalah analisis regresi linier berganda.

Data yang digunakan pada penelitian ini dibedakan menjadi 2 macam berdasarkan sumbernya, yaitu data primer dan data sekunder. Data primer yang dibutuhkan adalah jumlah kendaraan menuju atau meninggalkan sekolah berdasarkan jenis moda dan karakteristik pelaku pergerakan. Data jumlah kendaraan diperoleh melalui survei traffic counting secara manual pada satu hari kerja, mulai dari pukul 06.30 hingga pukul 16.30 WIB. Kendaraan yang diamati adalah sepeda motor (SM), kendaraan ringan (KR), kendaraan berat (KB), dan kendaraan tak bermotor (KTB).

Data karakteristik pelaku pergerakan diperoleh melalui kuesioner yang disebar ke murid-murid pada 5 sekolah yang diamati. Karena populasi yang cukup besar, pada studi ini digunakan teknik probability sampling; secara spesifik yang digunakan pada penelitian ini adalah teknik Cluster Random Sampling, di mana populasi terdiri atas kelompok-kelompok individu atau cluster (Susilana, 2015). Ukuran sampel ditentukan dengan menggunakan rumus Slovin, dengan tingkat kepercayaan 90\%. Total kuesioner yang disebar adalah sebanyak 132, dengan pertanyaan yang diajukan mencakup jumlah anggota keluarga, jumlah uang saku, moda transportasi yang digunakan untuk ke sekolah, serta jarak dari tempat tinggal ke sekolah. Data sekunder diperoleh dari pihak sekolah serta dari situs Direktorat Jenderal Pendidikan Dasar dan Menengah, yang terdiri atas jumlah guru, jumlah tenaga kependidikan, jumlah murid, dan jumlah ruang kelas.

\section{HASIL DAN PEMBAHASAN}

Bangkitan pergerakan merupakan perkiraan atas jumlah pergerakan yang berasal dari zona tertentu atau tertarik ke zona tertentu (Tamin, 1997). Analisis dikerjakan menggunakan metode regresi linier berganda, dengan variabel tidak bebas (Y) pada bangkitan adalah jumlah kendaraan yang meninggalkan sekolah, dan pada tarikan jumlah kendaraan yang menuju sekolah pada tarikan (Y). Variabel bebas yang digunakan diperoleh berdasarkan sintesis tinjauan literatur dan studi penelitian terdahulu, yaitu jumlah murid, jumlah guru dan tenaga kependidikan, jumlah anggota keluarga, jumlah uang saku per hari, jarak dari tempat tinggal ke sekolah, serta jumlah ruang kelas.

Pengerjaan analisis regresi linier berganda pada penelitian ini dilakukan dengan SPSS menggunakan metode enter, yaitu metode yang mana semua variabel dikalkulasi berdasarkan kriteria (default) SPSS (Sarwono, 2017). Metode Enter dipilih karena semua variabel bebas yang digunakan pada penelitian ini dianggap berpengaruh, sehingga tidak perlu dilakukan eliminasi dalam proses analisis dengan SPSS.

Berdasarkan analisis regresi linier berganda yang telah dilakukan dengan SPSS, diperoleh model untuk menggambarkan jumlah bangkitan dan tarikan pergerakan di kawasan 
penelitian serta faktor yang memengaruhinya. Rangkuman hasil analisis tersebut disajikan pada Tabel 1.

Tabel 1 Hasil Bangkitan dan Tarikan Pergerakan

\begin{tabular}{lll}
\hline & \multicolumn{1}{c}{ Bangkitan $(\mathrm{Y})$} & \multicolumn{1}{c}{ Tarikan $(\mathrm{Z})$} \\
\hline Persamaan & $\mathrm{Y}=509,971+24,280 \mathrm{X}_{1}-0,026 \mathrm{X}_{2}$ & $\mathrm{Z}=494,835+11,330 \mathrm{X}_{1}-0,029 \mathrm{X}_{2}$ \\
Faktor yang memengaruhi & $\mathrm{X}_{1}$ : jumlah ruang kelas & $\mathrm{X}_{1}$ : jumlah guru dan tendik \\
& $\mathrm{X}_{2}$ : jumlah uang saku per hari & $\mathrm{X}_{2}$ : jumlah uang saku per hari \\
$\mathrm{R}^{2}$ & 0,928 & 0,92 \\
Signifikansi (Sig.) & 0,072 & 0,08 \\
\hline
\end{tabular}

Dari model bangkitan pergerakan yang terbentuk dapat diketahui bahwa faktor yang memengaruhi bangkitan pergerakan di wilayah penelitian adalah jumlah ruang kelas dan jumlah uang saku per hari (variabel bebas). Melihat nilai $\mathrm{R}^{2}$, kedua variabel bebas tersebut dapat menjelaskan bangkitan pergerakan (variabel tidak bebas) sebesar 92,8\%. Dengan nilai signifikansi sebesar 0,072 (lebih kecil daripada 0,1), model ini tepat untuk memprediksi bangkitan pergerakan di wilayah penelitian. Melalui persamaan yang ada pada Tabel 1, disimpulkan bahwa jumlah bangkitan pergerakan di wilayah penelitian akan semakin tinggi apabila jumlah ruang kelas meningkat.

Jumlah ruang kelas dapat menggambarkan jumlah murid dalam satu sekolah. Semakin banyak jumlah ruang kelas yang disediakan sekolah, semakin banyak murid yang dapat diterima, dan bangkitan pergerakannya akan semakin besar, karena semua murid yang bersekolah di kawasan ini bergerak dan tiba di waktu yang bersamaan. Di wilayah yang diamati ini, KB/TK Fransiskus Bandar Lampung memiliki 6 ruang kelas dan 112 murid, SD Fransiskus 2 Bandar Lampung memiliki 24 kelas dan 619 murid, SD Negeri 2 Rawa Laut Bandar Lampung memiliki 46 kelas dan 1.475 murid, SMP Xaverius 2 Bandar Lampung memiliki 12 kelas dan 418 murid, serta SMA Xaverius Bandar Lampung memiliki 21 kelas dan 727 murid.

Selain itu, jumlah ruang kelas juga berkaitan dengan waktu sekolah yang berdekatan atau bersamaan merupakan salah satu penyebab kemacetan lalu lintas di kawasan pendidikan. KB/TK Fransiskus 2 Bandar Lampung, SD Fransiskus 2 Bandar Lampung, SMP Xaverius 2 Bandar Lampung, dan SMA Xaverius 2 Bandar Lampung memulai kegiatan belajar-mengajar pada pukul 07.00 WIB, dan SD Negeri 2 Rawa Laut Bandar Lampung memulai kegiatannya pada pukul 07.15 WIB. KB/TK Fransiskus 2 Bandar Lampung mengakhiri kegiatan belajar-mengajar mereka pada pukul 10.00 WIB, yang bersamaan dengan waktu pulang murid kelas 1 dan waktu masuk kelas 2 SD Negeri 2 Rawa Laut Bandar Lampung. SD Fransiskus 2 Bandar Lampung mengakhiri kegiatan belajar-mengajarnya pada waktu yang berdekatan, yaitu pukul 12.50 WIB (kelas 1), 13.30 (kelas 2), dan 14.00 (kelas 3-6). Sedangkan SMP Xaverius Bandar Lampung serta SMA Xaverius Bandar Lampung mengakhiri kegiatan belajar-mengajar mereka pada waktu yang berdekatan, yaitu pukul 15.00 WIB untuk SMP dan pukul 15.15 WIB untuk SMA. 




Gambar 2 Peta Asal Tempat Tinggal Murid Sekolah di Wilayah Penelitian

Berdasarkan temuan studi (Gambar 2), pelaku pergerakan di wilayah penelitian didominasi oleh murid yang berdomisili di Kecamatan Kedamaian dan Kecamatan Way Halim. Hal ini dikarenakan 5 sekolah di wilayah penelitian tidak menerapkan sistem zonasi, sehingga siapa saja dapat mendaftar di sekolah tersebut. Jarak rata-rata tempat tinggal murid KB/TK Fransiskus Bandar Lampung dengan sekolahnya adalah 3,28 km, SD Fransiskus 2 Bandar Lampung sejauh 5,33 km, SD Negeri 2 Rawa Laut Bandar Lampung sejauh 5,47 km, SMP Xaverius 2 Bandar Lampung sejauh 4,91 km, dan SMA Xaverius Bandar Lampung sejauh 5,62 km. Karena jarak tempat tinggal yang cukup jauh, pergerakan menuju sekolah dilakukan dengan kendaraan. Berdasarkan total 132 kuesioner yang disebarkan ke 5 sekolah, 45\% murid diantar menggunakan sepeda motor, 39\% diantar menggunakan mobil pribadi, $7 \%$ mengendarai sepeda motor (murid SMA), 5\% menggunakan mobil jemputan, $2 \%$ menggunakan ojek online, serta $1 \%$ mengendarai mobil (murid SMA).

Sedangkan dari model tarikan pergerakan yang terbentuk, dapat diketahui bahwa faktor yang memengaruhi tarikan pergerakan di wilayah penelitian adalah jumlah guru dan tenaga kependidikan, serta jumlah uang saku per hari (variabel bebas). Melihat nilai $\mathrm{R}^{2}$, kedua variabel bebas tersebut dapat menjelaskan bangkitan pergerakan (variabel tidak bebas) sebesar 92\%. Dengan nilai signifikansi sebesar 0,08 (lebih kecil daripada 0,1), model ini tepat untuk memprediksi tarikan pergerakan di wilayah penelitian. Melalui persamaan yang ada pada Tabel 1 dapat disimpulkan bahwa jumlah tarikan pergerakan di wilayah penelitian semakin tinggi apabila jumlah guru dan tenaga kependidikan meningkat. Guru dan tenaga kependidikan merupakan salah satu pelaku pergerakan yang selalu menuju 
sekolah secara konsisten untuk tujuan bekerja atau melakukan pergerakan untuk aktivitas ekonomi. Adapun jumlah guru dan tenaga kependidikan di KB/TK Fransiskus 2 Bandar Lampung sebanyak 16 orang, SD Fransiskus 2 Bandar Lampung sebanyak 36 orang, SD Negeri 2 Rawa Laut Bandar Lampung sebanyak 67 orang, SMP Xaverius 2 Bandar Lampung sebanyak 24 orang, dan SMA Xaverius Bandar Lampung sebanyak 52 orang.

\section{KESIMPULAN}

Bangkitan dan tarikan pergerakan yang dihasilkan oleh kawasan pendidikan yang ada di Jalan Cendana-Jalan Ir. H. Juanda, Kota Bandar Lampung, cukup besar dan memengaruhi lalu lintas, terutama di pagi hari, karena semua murid yang bersekolah di kawasan tersebut serta guru dan tenaga kependidikan yang bekerja di kawasan tersebut bergerak dan tiba di waktu yang bersamaan. Berdasarkan temuan studi ini, pelaku pergerakan di wilayah penelitian didominasi oleh murid yang berdomisili di Kecamatan Kedamaian dan Kecamatan Way Halim, karena 4 sekolah di wilayah penelitian tidak menerapkan sistem zonasi, sehingga siapa saja dapat mendaftar di sekolah tersebut. Selain itu, kelima sekolah yang ada di wilayah penelitian telah berdiri sekitar 60 tahun yang lalu dan saat ini memiliki akreditasi A, sehingga sekolah telah dikenal dan memiliki reputasi yang baik. Faktor-faktor yang memengaruhi bangkitan dan tarikan pergerakan pada kawasan pendidikan di Jalan Cendana dan Jalan Ir. H. Juanda, Kota Bandar Lampung, adalah jumlah ruang kelas, yang berkaitan dengan waktu sekolah, jumlah murid, dan jarak tempat tinggal murid dari rumah ke sekolah, jumlah guru dan tenaga kependidikan, serta jumlah uang saku murid per hari.

Melihat karakteristik pelaku pergerakan, terdapat beberapa rekomendasi terkait pergerakan yang terjadi di wilayah penelitian, untuk mendukung transportasi berkelanjutan, yaitu:

1) Menyediakan lahan parkir komunal untuk mengurangi kegiatan parkir di pinggir jalan.

Rekomendasi ini diberikan karena lokasi sekolah yang berdekatan dan tidak memungkinkan bagi masing-masing sekolah untuk menyediakan lahan parkir.

2) Mengembangkan transportasi umum, seperti bus sekolah, dan memberdayakan mobil antar-jemput sebagai alternatif untuk mengurangi jumlah kendaraan yang melintas pada jam masuk dan jam pulang sekolah.

\section{DAFTAR PUSTAKA}

Creswell, J.W. 2003. Research Design: Qualitative, Quantitative, and Mixed Methods Approaches. Los Angeles, CA: SAGE Publishing.

Ilyani, M. 2012. Reduksi Panjang Perjalanan sebagai Implikasi Pemanfaatan Fasilitas Pendidikan Sekolah Dasar Terdekat dari Tempat Tinggal. Jurnal Perencanaan Wilayah dan Kota, 23 (3): 209-224. 
Manoppo, M.R. dan Sendow, T.K. 2011. Analisa Bangkitan Pergerakan dan Distribusi Perjalanan di Kota Manado. Jurnal Ilmiah MEDIA ENGINEERING, 1 (1): 17-23.

Ortúzar, J.d. dan Willumsen, L.G. 1990. Modelling Transport 4th Edition. Hoboken, NJ: John Wiley and Sons, Ltd.

Sarwono, J. 2017. Mengenal Prosedur-Prosedur Populer dalam SPSS 23. Jakarta: PT Elex Media Komputindo.

Septomiko, Y. 2014. Permodelan Bangkitan pada Tata Guna Lahan Sekolah Menengah Atas Swasta di Palembang. Jurnal Teknik Sipil dan Lingkungan Universitas Sriwijaya, 2 (2): 282-286.

Sholichin, I. 2011. Analisa Bangkitan Perjalanan dan Trip Distribution di Surabaya Utara. Jurnal Teknik Sipil KERN, 1 (2): 13-22.

Susilana, R. 2015. Modul 6 Populasi dan Sampel. Modul Praktikum. Bandung: Universitas Pendidikan Indonesia.

Tamin, O.Z. 1997. Perencanaan dan Pemodelan Transportasi: Teori, Contoh Soal, dan Aplikasi. Edisi Ketiga. Bandung: Penerbit ITB.

Wahyuningsih, A.R., Riyanto, A., dan Munawar, A. 2013. Analisis Bangkitan dan Tarikan Perjalanan: Studi Kasus Pada Tata Guna Lahan Rumah Sakit Umum di Klaten. Surakarta: Universitas Muhammadiyah Surakarta. 